\title{
Rapid and efficient transfer of the T cell aging marker CD57 from glioblastoma stem cells to CAR T cells
}

\author{
Xuekai Zhu ${ }^{1,2}$, Gabriele Niedermann ${ }^{1,2}$ \\ ${ }^{1}$ Department of Radiation Oncology, University Hospital Freiburg, Freiburg, Germany \\ ${ }^{2}$ German Cancer Consortium (DKTK), Freiburg, and German Cancer Research Center (DKFZ), Heidelberg, Germany \\ Correspondence to: Xuekai Zhu, email: xuekai.zhu@uniklinik-freiburg.de \\ Gabriele Niedermann, email: gabriele.niedermann@uniklinik-freiburg.de \\ Keywords: CD57, trogocytosis, chimeric antigen receptor, cancer stem cells, glioblastoma \\ Received: March 05, $2015 \quad$ Accepted: May 6, $2015 \quad$ Published: May 15, 2015
}

This is an open-access article distributed under the terms of the Creative Commons Attribution License, which permits unrestricted use, distribution, and reproduction in any medium, provided the original author and source are credited.

\section{ABSTRACT}

\begin{abstract}
Adoptive transfer of $T$ cells expressing chimeric antigen receptors (CARs) holds great promise for cancer treatment. We recently developed CAR T cells targeting the prototypic cancer stem cell marker AC133 and showed that these CAR T cells killed AC133+ glioblastoma stem cells (GBM-SCs) in vitro and inhibited the growth of brain tumors initiated from GBM-SCs in xenograft mouse models in vivo. Upon coincubation with GBM-SCs, we observed strong upregulation of the T cell aging marker CD57, but other phenotypical or functional changes usually associated with terminal T cell differentiation could not immediately be detected. Here, we provide evidence suggesting that CD57 is rapidly and efficiently transferred from CD57+ GBM-SCs to preactivated $T$ cells and that the transfer is greatly enhanced by specific CAR/ligand interaction. After separation from CD57+ tumor cells, CD57 epitope expression on T cells decreased only slowly over several days. We conclude that CD57 transfer from tumor cells to $\mathrm{T}$ cells may occur in patients with CD57+ tumors and that it may have to be considered in the interpretation of phenotyping results for tumor-infiltrating lymphocytes and perhaps also in the characterization of tumor-specific $T$ cells from tumor or lymph node homogenates or peripheral blood mononuclear cells.
\end{abstract}

\section{INTRODUCTION}

Tumor-specific chimeric antigen receptors (CARs) are recombinant molecules consisting of an antibody moiety specific for a tumor cell surface antigen fused to intracellular signaling domains of the physiological $\mathrm{T}$ cell receptor (TCR) and of costimulatory receptors [1]. Engineered $\mathrm{T}$ cells expressing CARs are therefore capable of recognizing tumor cells in a major histocompatibility complex (MHC)independent manner, resulting in $\mathrm{T}$ cell activation and killing of bound target cells. CAR T cells have shown extraordinarily high activity against CD19+ hematological malignancies [2,3], and great efforts are undertaken to develop CAR T cells for the treatment of other hematological malignancies and solid tumors.

We recently reported on CAR $\mathrm{T}$ cells recognizing the cancer stem cell (CSC) antigen AC133, an N-glycosylationdependent, stem cell-specific epitope of CD133, marking CSCs of many tumor entities including the highly malignant glioblastoma multiforme (GBM) $[4,5]$. These CAR T cells killed AC133+ tumor cells, including patient-derived glioblastoma stem cells (GBM-SCs), in vitro and in orthotopic tumor models in vivo [6].

The functionality of conventional $\mathrm{T}$ cells is impaired by the activation of negative regulatory immune checkpoints, $\mathrm{T}$ cell exhaustion and terminal $\mathrm{T}$ cell differentiation, i.e., processes that are induced by repetitive chronic TCRmediated stimulation [7-9]. The functionality of CAR T cells may also be compromised by these factors $[10,11]$. We therefore analyzed the expression of $\mathrm{T}$ cell surface markers indicative of the respective functional impairments.

Upon coincubation of CAR T cells with patient-derived GBM-SCs, we consistently observed an upregulation of CD57 [6], a terminally sulfated carbohydrate epitope best known as a marker for terminally differentiated, end-stage $\mathrm{T}$ cells $[12,13]$. Truly terminally differentiated $\mathrm{T}$ cells lose their proliferative capacity and expression of the positive costimulatory molecules CD27 and CD28, which usually correlates with loss of telomerase activity and critical shortening of the telomeres; in addition, they upregulate the cytotoxic granule molecules granzyme $\mathrm{B}$ and perforin $[7,12]$. 
However, we neither observed a loss of the proliferative capacity of CD57+ CAR T cells upon subsequent shortterm re-exposure to $\mathrm{AC} 133+$ target cells nor did we observe the downregulation of CD27 or CD28 [6]. Wu et al. [14] recently described a subpopulation of melanoma-specific CD8+ tumor-infiltrating lymphocytes (TILs) with hybrid phenotypic and functional properties of both an early effector-memory cell and a terminally differentiated effector cell co-expressing CD27, CD28, and CD57. These CD57+ $\mathrm{T}$ cells were classified as incompletely differentiated $\mathrm{T}$ cells. This TIL subpopulation lost CD27 expression and gained expression of the cytotoxic granule protein perforin after subsequent anti-CD3/anti-CD28-mediated stimulation, indicating transition to the terminally differentiated state.

We previously observed that CD57 expression on CAR T cells increased very rapidly (in less than $2 \mathrm{~h}$ ) and only upon coculture with patient-derived GBM-SCs, but not with conventional U251 glioma cells [6]. Since CD57 has been found on neuroblastoma and Ewing sarcoma cells with aggressive CSC-like features $[15,16]$, we investigated if CD57 was expressed by the GBM-SCs. CD57 was indeed expressed on all patient-derived GBM-SC lines studied, but it was not lost upon their differentiation, which let us conclude that CD57 is not a bona fide CSC marker for GBM [6].

The observation that CD57 increased on CAR T cells in less than a few hours and only upon encounter with CD57+ target cells suggested that proteins expressing CD57 carbohydrate epitopes may simply be transferred from CD57+ tumor cells to CAR T cells. In our previous work, we tried to prove the transfer of $\mathrm{CD} 57+$ proteins to $\mathrm{T}$ cells after prelabeling of CD57 on the tumor cells with a fluorescently labeled anti-CD57 antibody [6]. However, antibody binding may have hindered the intercellular transfer of $\mathrm{CD} 57+$ proteins onto the $\mathrm{T}$ cells. We have now obtained more evidence suggesting that CD57 is indeed rapidly and efficiently transferred from $\mathrm{CD} 57+$ tumor cells to prestimulated $\mathrm{T}$ cells and that this process is greatly enhanced by the specific CAR/ligand interaction.

We first evaluated the detailed kinetics of CD57 upregulation on $\mathrm{AC} 133$-specific CAR T cells upon coculture with CD57+ tumor cells. As shown in Figure 1, strong upregulation of CD57 on the T cells occurred very rapidly, within $10 \mathrm{~min}$, regardless of whether AC133-CAR or nontransfected (NT) prestimulated control CD8+ T cells were cocultured with AC133+ CD57+ NCH421k GBM-SCs. This ruled out the possibility that CD57 expression resulted from transcriptional and translational changes in the T cells, at least at the beginning of the coincubation period. Rather, it was likely the result of a direct transfer of the CD57+ proteins from the tumor cells to the $\mathrm{T}$ cells. The specific

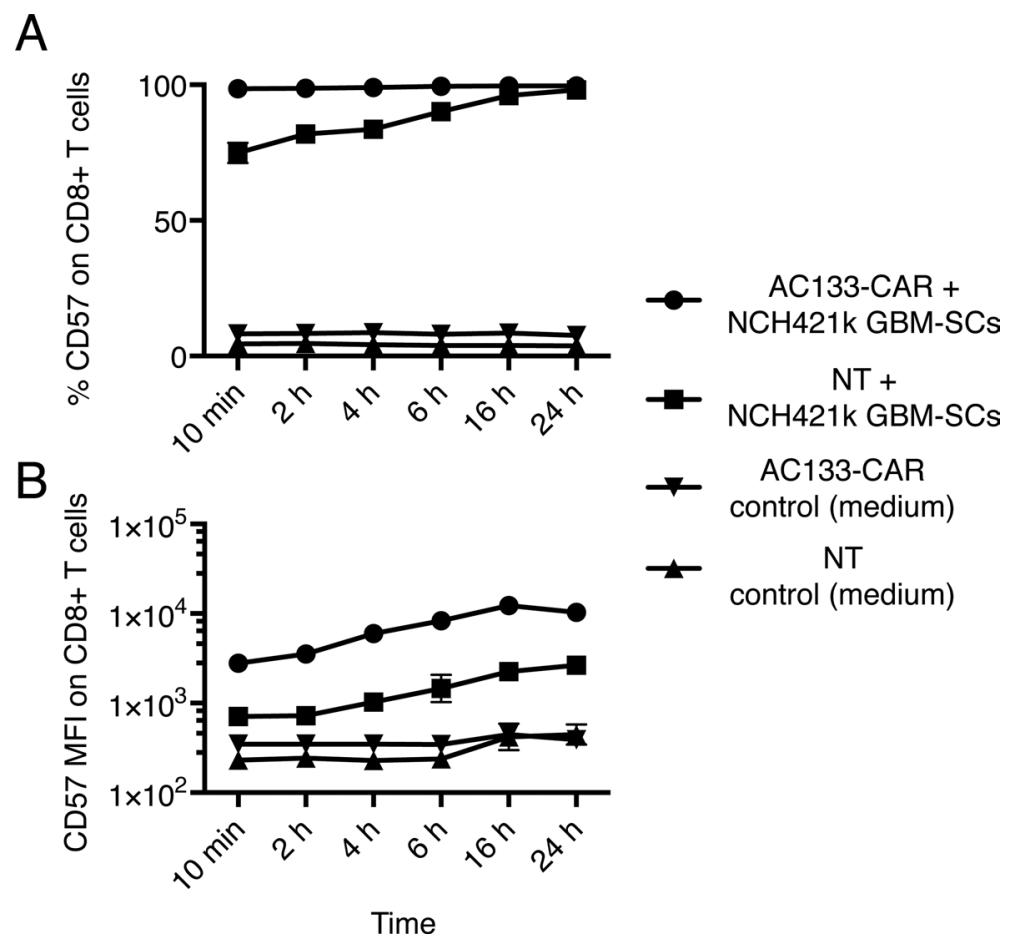

Figure 1: Kinetics of the gain of CD57 expression on T cells upon coincubation with CD57+ AC133+ NCH421k GBMSCs. AC133-CAR T cells or NT anti-CD3-prestimulated T cells were cocultured with NCH421k GBM-SCs at a ratio of 1:1 for the indicated periods of time. Thereafter, the percentage of CD57+ cells among the CD8 $+\mathrm{T}$ cells $(\mathbf{A})$ and the CD57 expression level on the T cells $(\mathbf{B})$ were assessed by flow cytometry (for details of Materials and Methods, see Ref. [6]). On the vast majority of AC133-CAR or NT T cells, CD57 expression was already detected within 10 min of coincubation; however, the per cell expression level was considerably higher on AC133CAR than on NT T cells. Data are representative of one out of three experiments, measured in triplicate, and are presented as mean $\pm \mathrm{SD}$. MFI, mean fluorescence intensity. 
CAR/ligand interaction strongly enhanced the transfer. Not only was the percentage of CD57+ T cells higher when CAR T cells were incubated with NCH421k GBM-SCs compared to NT T cells (Figure 1A), but also the mean fluorescence intensity (MFI) was higher (Figure 1B). The MFI for CD57 expression increased 7-26-fold for the AC133-CAR T cells while it increased only 2-6-fold for the NT control T cells at different time points of coincubation with AC133+ CD57+ tumor cells.

Since transfer of CD57 from tumor cells to T cells may affect the phenotyping of TILs isolated from tumor or lymph node homogenates or of tumor-specific T cells from peripheral blood mononuclear cells (PBMCs), we wanted to find out for how long CD57 can be detected on T cells after separation from the CD57+ tumor cells. As shown in Figure 2, 4 days after the separation of the AC133-specific CAR or NT control T cells from the AC133+ CD57+ NCH421k GBM-SCs, more than $90 \%$ of the CAR T cells or $80 \%$ of the NT cells were still CD57+ (Figure 2A). Although the MFI for CD57 expression on the CAR T cells had slowly and continuously dropped after separation from the tumor cells, CD57 was still significantly expressed after 4 days (Figure 2B, top panels). Of note, during this 4-day period, no strong CD57 expression was detected on the T cells when they had been preincubated with CD57- AC133+ tumor cells (Figure 2B, bottom panels); it is therefore unlikely that
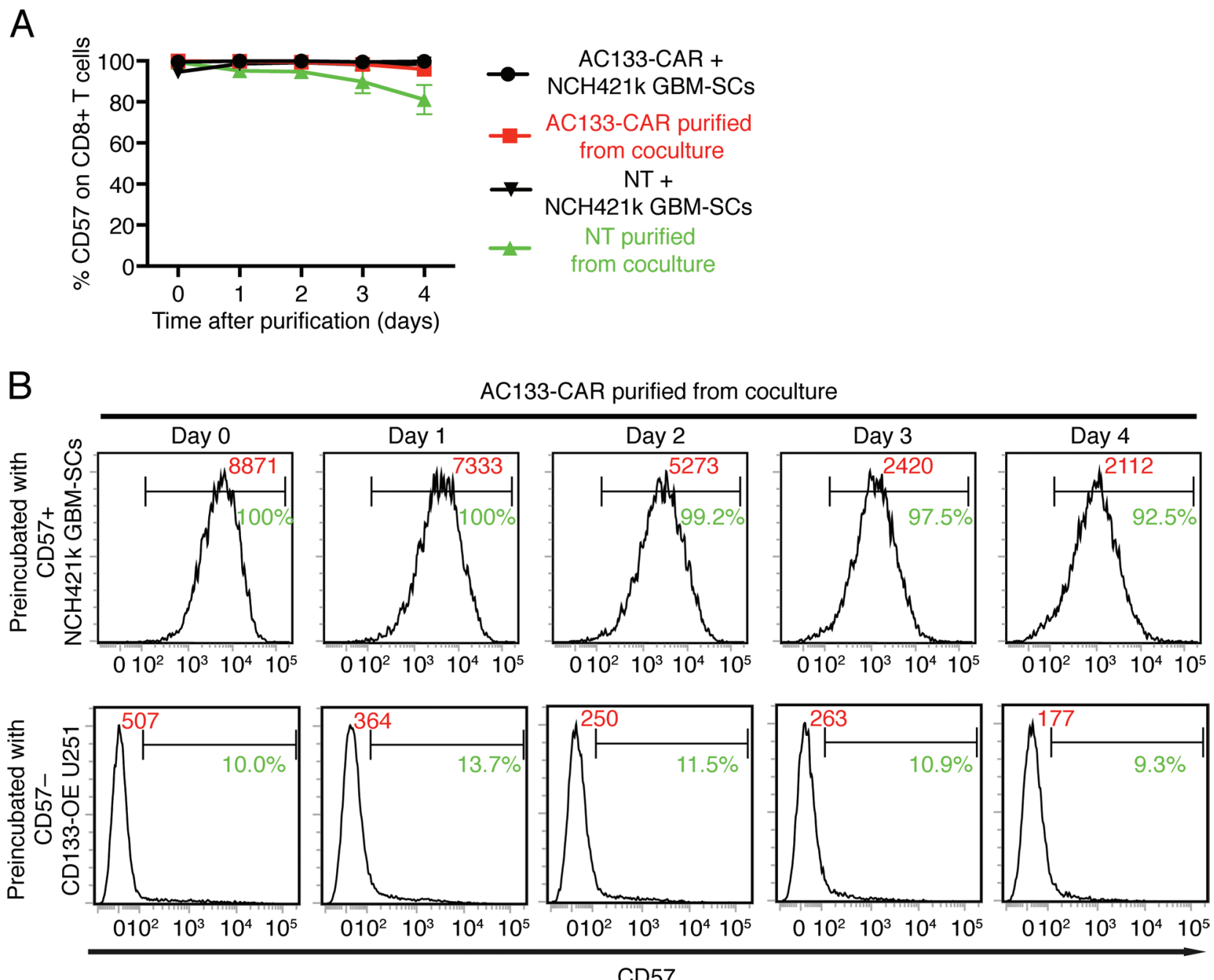

CD57

Figure 2: CD57 epitope expression on T cells decreases only slowly over a period of several days after separation from CD57+ tumor cells. AC133-CAR T cells or NT control T cells were cocultured with CD57+ AC133+ NCH421k GBM-SCs or CD57$\mathrm{AC} 133+\mathrm{CD} 133-\mathrm{OE}$ U251 cells at a ratio of 1:1 for $4 \mathrm{~h}$. Thereafter, CD8+ T cells were purified from the coculture using the EasySep ${ }^{\mathrm{TM}}$ Human CD8 Positive Selection Kit (STEMCELL Technologies). After separation, the T cells were cultured in T cell medium for the indicated periods of time and CD57 expression was then determined by flow cytometry (for details of Materials and Methods, see Ref. [6]). (A) Percentage of CD57+ cells among the CD8 $+\mathrm{T}$ cells at the indicated time periods after separation from the CD57+ tumor cells. Data are representative of one out of three experiments, measured in triplicate, and are presented as mean $\pm \mathrm{SD}$. (B) Representative flow cytometry results. The percentage of CD57+ cells among the CD8+ CAR T cells is indicated in green; the MFI is given in red. 
A

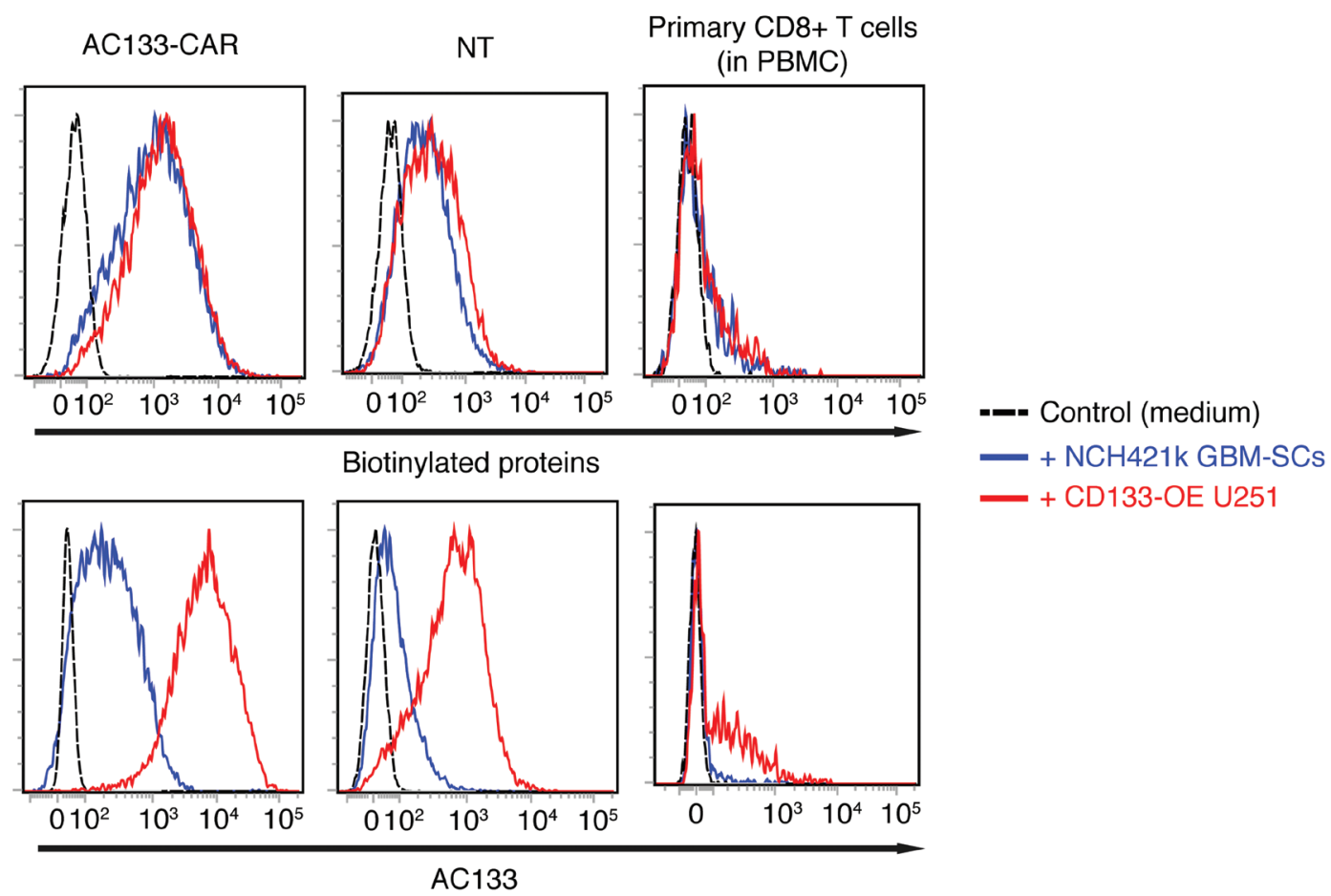

B

AC133-CAR purified from coculture
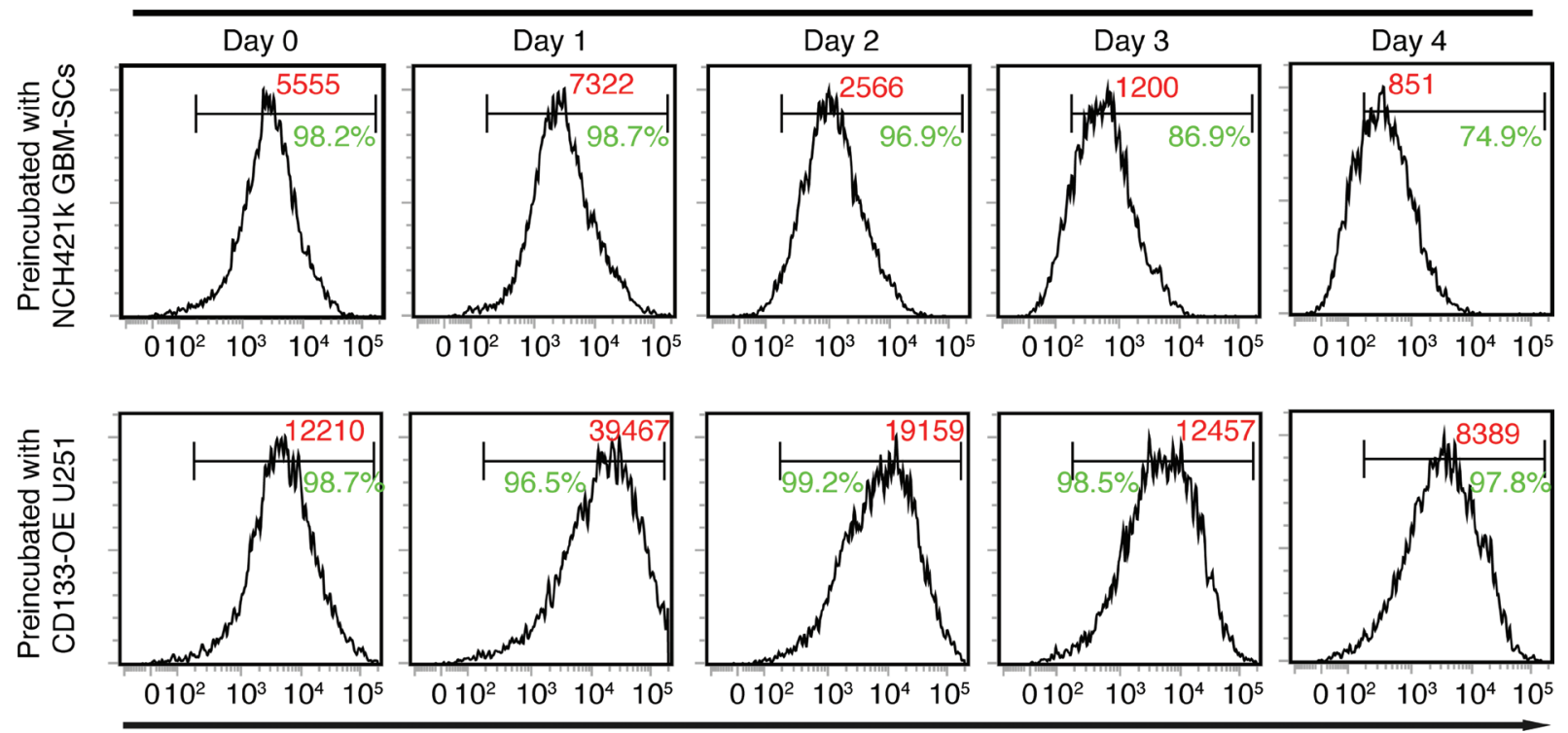

Biotinylated proteins

Figure 3: Transfer of biotinylated proteins and AC133 from glioma cells to preactivated CD8+ T cells. For biotinylation of AC133+ glioma cells, either NCH421k GBM-SCs or CD133-OE U251 cells were incubated with EZ-Link Sulfo-NHS-LC-Biotin (Pierce ${ }^{\mathrm{TM}}$ ) following the manufacturer's protocol. AC133-specific CAR T cells, NT anti-CD3-prestimulated T cells, or PBMCs were cocultured with biotinylated tumor cells at a ratio of 1:1 for $4 \mathrm{~h}$. Thereafter, expression levels of biotinylated proteins (after staining with PE-streptavidin, Biolegend) or AC133 (after staining with anti-AC133 as described in Ref. [6]) were determined by flow cytometry (A). (B) To determine for how long the transferred biotinylated proteins can be detected on the separated T cells, CD8+ T cells were isolated from the coculture and further cultured in T cell medium for 4 days, as described in the legend to Figure 2. At the indicated periods of time after separation, the percentage of biotin + cells among the CD8 + CAR T cells was determined by flow cytometry and is indicated in green; the MFI is given in red. Data presented are representative of at least three independent experiments. 
the high CD57 expression level on the T cells during the 4-day period following incubation with the CD57+ tumor cells was due to endogenous expression by the $\mathrm{T}$ cells. Taken together, these results suggest that CD57 transfer from CD57+ tumor cells to T cells could indeed contribute to $\mathrm{CD} 57$ expression on tumor-specific $\mathrm{T}$ cells isolated from tumor or lymph node homogenates or PBMCs of patients with CD57+ tumors.

The aforementioned findings suggest that $\mathrm{T}$ cells might gain CD57 via trogocytosis $[17,18]$, a process where membrane fragments are directly transferred between cells within a few minutes and are detectable on the recipient cells for a considerable period of time [19-21]. Via trogocytosis, a wide range of proteins are usually transferred between cells. Therefore, we wanted to figure out if membrane proteins other than CD57 were transferred between tumor cells and T cells. For this purpose, we studied the transfer of biotinylated membrane proteins or AC133. In these experiments, AC133specific CAR T cells, NT control T cells, or primary CD8+ $\mathrm{T}$ cells from PBMCs were incubated with biotinylated NCH421k GBM-SCs or CD133-overexpressing U251 glioma cells (CD133-OE U251), which exhibit 10-15-fold higher AC133 expression than NCH421k GBM-SCs [6,22]. As shown in Figure 3A, we indeed observed that not only AC133 but also biotinylated proteins were transferred from glioma cells to $\mathrm{CD} 8+\mathrm{T}$ cells. The transfer of biotinylated membrane proteins (Figure 3A, top panels) was influenced by two factors: (i) the activation status of the T cells (high transfer only occurred onto anti-CD3-prestimulated CAR $\mathrm{T}$ and NT T cells but not onto primary CD8+ T cells) and (ii) the expression of the tumor-specific CAR (much more biotinylated proteins were transferred onto AC133-CAR $\mathrm{T}$ cells than onto NT T cells). The transfer of AC133 (Figure 3A, bottom panels) was also strongly influenced by the AC133 expression level on the tumor cells (much more
AC133 was transferred from CD133-OE U251 cells than from NCH421k GBM-SCs). An influence of the molecule level on the tumor cells was also observed in our previous report [6] for CD57 upregulation on T cells (higher CD57 expression on GBM-SCs conferred higher upregulation of CD57 on CAR T cells after coincubation). Similar to what we observed for CD57 (see Figure 2), the biotinylated proteins transferred from the tumor cells to the CAR T cells were detectable for at least 4 days on the $T$ cell surface after separation from the tumor cells (Figure 3B).

As shown in Figure 3A, only a minor fraction of the primary $\mathrm{CD} 8+\mathrm{T}$ cells acquired biotinylated proteins and AC133 from the tumor cells. To figure out if membrane proteins were also transferred onto naïve $\mathrm{CD} 8+\mathrm{T}$ cells, we compared the amount of biotinylated proteins and $\mathrm{AC} 133$ between naïve $\mathrm{T}$ cells $(\mathrm{CD} 45 \mathrm{RA}+\mathrm{CD} 62 \mathrm{~L}+)$ and memory $\mathrm{T}$ cells $(\mathrm{CD} 45 \mathrm{RO}+)$ upon coincubation of PBMCs with the tumor cells. Both naïve and memory $T$ cells acquired proteins from tumor cells, although the memory $\mathrm{T}$ cells acquired more proteins (data not shown).

The data presented here suggest an extremely rapid and efficient transfer of CD57 from AC133+ CD57+ tumor cells to AC133-specific CAR T cells. Together with our previous findings [6], the data suggest that CD57 expression on tumor-specific $\mathrm{T}$ cells does not always indicate terminal or near-terminal $\mathrm{T}$ cell differentiation and that it could, at least in part, also simply reflect a recent encounter with CD57+ tumor cells. Furthermore, the data strongly suggest that the CD57 transfer is greatly increased by specific, receptormediated interaction between the tumor cells and T cells (Figure 4). This transfer likely occurs through trogocytosis. For conventional $\mathrm{T}$ cells, evidence of membrane protein transfer from antigen-presenting cells or tumor cells by trogocytosis facilitated by specific peptide-MHC/TCR interaction has already been reported [23]. We now report

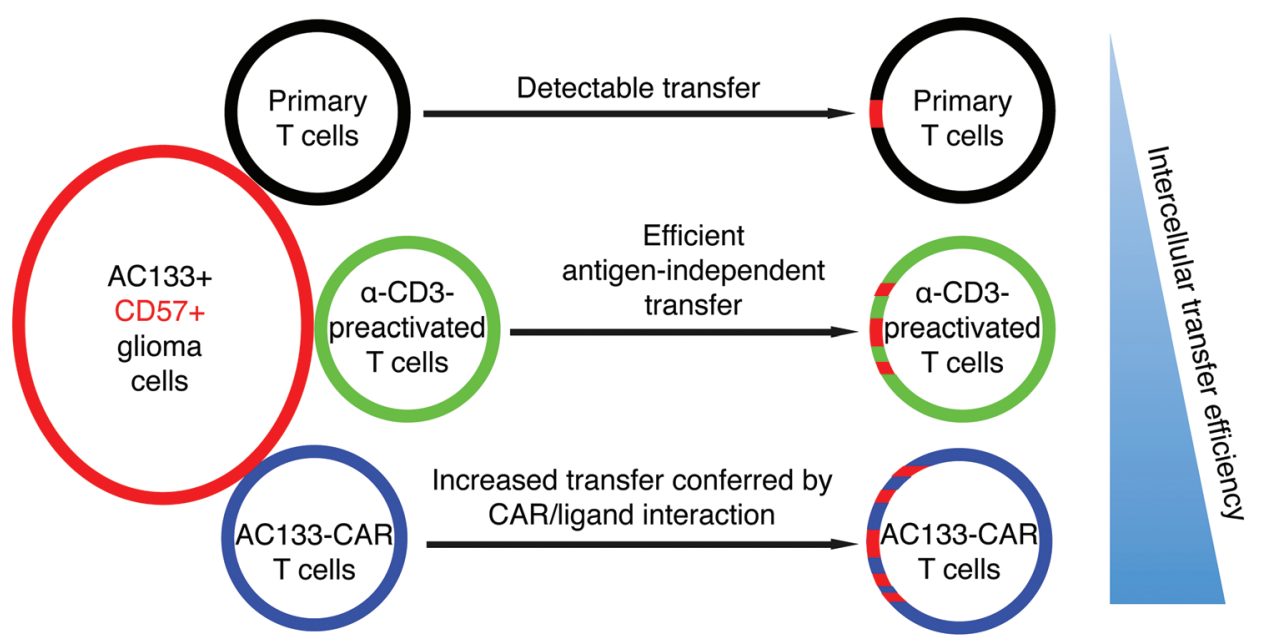

Figure 4: Schematic representation of the intercellular transfer efficiency of membrane proteins from glioma cells to CD8+ T cells. The experimental data suggest that primary CD8+ T cells acquire only low amounts of protein from tumor cells. Transfer to polyclonal T cells prestimulated with anti-CD3 (as described in Ref. [6]) is much higher and is further considerably increased by specific CAR/ligand interaction. 
evidence that the intercellular transfer of membrane proteins to $T$ cells is also greatly facilitated by specific CAR/CAR target interaction. However, CD57 was also transferred to anti-CD3-prestimulated control $\mathrm{T}$ cells, albeit to a lesser extent (Figure 4). Transfer to primary or naïve $\mathrm{T}$ cells was negligible. Intercellular transfer of CD57 from tumor cells to $\mathrm{T}$ cells may have to be considered in the interpretation of phenotyping results for TILs from CD57+ tumor entities such as brain tumors [6,24-26] and neuroectodermal tumors (including neuroblastoma, Ewing's sarcoma, and melanoma $[15,16,27,28])$, at least in case of in situ analyses such as immunohistochemical analyses. Since the CD57 levels on $\mathrm{T}$ cells only slowly decreased over several days after separation from CD57+ tumor cells, the intercellular transfer may even contribute to CD57 expression on effector/ memory $\mathrm{T}$ cells in PBMCs from patients with CD57+ tumors.

\section{ACKNOWLEDGMENTS}

We would like to thank Dr. Mark Kroenke for his scientific input.

\section{REFERENCES}

1. Sadelain M, Brentjens R, Riviere I. The basic principles of chimeric antigen receptor design. Cancer Discov. 2013; 3: 388-398.

2. Eshhar Z. From the Mouse Cage to Human Therapy: A Personal Perspective of the Emergence of T-bodies/ Chimeric Antigen Receptor T Cells. Hum Gene Ther. 2014; 25: 773-778.

3. Maus MV, Grupp SA, Porter DL, June CH. Antibodymodified T cells: CARs take the front seat for hematologic malignancies. Blood. 2014; 123: 2625-2635.

4. Yan K, Yang K, Rich JN. The evolving landscape of glioblastoma stem cells. Curr Opin Neurol. 2013; 26: 701707.

5. Grosse-Gehling $\mathrm{P}$, Fargeas CA, Dittfeld C, Garbe Y, Alison MR, Corbeil D, Kunz-Schughart LA. CD133 as a biomarker for putative cancer stem cells in solid tumours: limitations, problems and challenges. J Pathol. 2013; 229: $355-378$

6. Zhu X, Prasad S, Gaedicke S, Hettich M, Firat E, Niedermann G. Patient-derived glioblastoma stem cells are killed by CD133-specific CAR T cells but induce the $\mathrm{T}$ cell aging marker CD57. Oncotarget. 2015; 6: 171-184.

7. Akbar AN, Henson SM. Are senescence and exhaustion intertwined or unrelated processes that compromise immunity? Nat Rev Immunol. 2011; 11: 289-295.

8. Restifo NP, Gattinoni L. Lineage relationship of effector and memory T cells. Curr Opin Immunol. 2013; 25: 556-563.

9. Becker JC, Andersen MH, Schrama D, Thor Straten P. Immunesuppressive properties of the tumor microenvironment. Cancer Immunol Immunother. 2013; 62: 1137-1148.

10. John LB, Devaud C, Duong CP, Yong CS, Beavis PA, Haynes NM, Chow MT, Smyth MJ, Kershaw MH, Darcy PK. Anti-
PD-1 antibody therapy potently enhances the eradication of established tumors by gene-modified T cells. Clin Cancer Res. 2013; 19: 5636-5646.

11. Hombach AA, Abken H. Young $\mathrm{T}$ Cells Age During a Redirected Anti-Tumor Attack: Chimeric Antigen ReceptorProvided Dual Costimulation is Half the Battle. Front Immunol. 2013; 4: 135.

12. Strioga M, Pasukoniene V, Characiejus D. CD8+ CD28- and CD8 + CD57+ $\mathrm{T}$ cells and their role in health and disease. Immunology. 2011; 134: 17-32.

13. Focosi D, Bestagno M, Burrone O, Petrini M. CD57+ T lymphocytes and functional immune deficiency. J Leukoc Biol. 2010; 87: 107-116.

14. Wu RC, Liu S, Chacon JA, Wu S, Li Y, Sukhumalchandra P, Murray JL, Molldrem JJ, Hwu P, Pircher H, Lizee G, Radvanyi LG. Detection and characterization of a novel subset of CD8(+)CD57(+) T cells in metastatic melanoma with an incompletely differentiated phenotype. Clin Cancer Res. 2012; 18: 2465-2477.

15. Schlitter AM, Dorneburg C, Barth TF, Wahl J, Schulte JH, Bruderlein S, Debatin KM, Beltinger C. CD57(high) neuroblastoma cells have aggressive attributes ex situ and an undifferentiated phenotype in patients. PLoS One. 2012; 7: e42025.

16. Wahl J, Bogatyreva L, Boukamp P, Rojewski M, van Valen F, Fiedler J, Hipp N, Debatin KM, Beltinger C. Ewing's sarcoma cells with CD57-associated increase of tumorigenicity and with neural crest-like differentiation capacity. Int J Cancer. 2010; 127: 1295-1307.

17. Joly E, Hudrisier D. What is trogocytosis and what is its purpose? Nat Immunol. 2003; 4: 815.

18. Davis DM. Intercellular transfer of cell-surface proteins is common and can affect many stages of an immune response. Nat Rev Immunol. 2007; 7: 238-243.

19. Vanherberghen B, Andersson K, Carlin LM, Nolte-'t Hoen EN, Williams GS, Hoglund P, Davis DM. Human and murine inhibitory natural killer cell receptors transfer from natural killer cells to target cells. Proc Natl Acad Sci U S A. 2004; 101: 16873-16878.

20. LeMaoult J, Caumartin J, Daouya M, Favier B, Le Rond S, Gonzalez A, Carosella ED. Immune regulation by pretenders: cell-to-cell transfers of HLA-G make effector T cells act as regulatory cells. Blood. 2007; 109: 2040-2048.

21. Bonaccorsi I, Morandi B, Antsiferova O, Costa G, Oliveri D, Conte R, Pezzino G, Vermiglio G, Anastasi GP, Navarra G, Munz C, Di Carlo E, Mingari MC, et al. Membrane transfer from tumor cells overcomes deficient phagocytic ability of plasmacytoid dendritic cells for the acquisition and presentation of tumor antigens. J Immunol. 2014; 192: 824-832.

22. Gaedicke S, Braun F, Prasad S, Machein M, Firat E, Hettich M, Gudihal R, Zhu X, Klingner K, Schuler J, Herold-Mende CC, Grosu AL, Behe M, et al. Noninvasive positron emission tomography and fluorescence imaging of CD133+ tumor stem cells. Proc Natl Acad Sci U S A. 2014; 111: E692-701.

23. Hudrisier D, Riond J, Mazarguil H, Gairin JE, Joly E. Cutting edge: CTLs rapidly capture membrane fragments from target cells in a TCR signaling-dependent manner. J Immunol. 
2001; 166: 3645-3649.

24. Qi L, Huang Y-1, Kogiso M, Mao H, Baxter P, Su JMF, Perlaky L, Lau CC, Chintagumpala M, Li X-N. Abstract 1484: CD57 defines a novel maker of glioblastoma stem cells that have greater invasive potential than CD133+ tumor cells. Cancer Research. 2014; 74: 1484.

25. Bilzer T, Stavrou D, Dahme E, Keiditsch E, Burrig KF, Anzil AP, Wechsler W. Morphological, immunocytochemical and growth characteristics of three human glioblastomas established in vitro. Virchows Arch A Pathol Anat Histopathol. 1991; 418: 281-293.

26. Leong ASY, Cooper K, Leong FJWM. (2003). Manual of diagnostic antibodies for immunohistology: Cambridge University Press).

27. Thies A, Schachner M, Berger J, Moll I, Schulze HJ, Brunner G, Schumacher U. The developmentally regulated neural crest-associated glycotope HNK-1 predicts metastasis in cutaneous malignant melanoma. J Pathol. 2004; 203: 933939.

28. Gershon TR, Oppenheimer O, Chin SS, Gerald WL. Temporally regulated neural crest transcription factors distinguish neuroectodermal tumors of varying malignancy and differentiation. Neoplasia. 2005; 7: 575-584. 